\title{
Acceptability of HIV Testing and Counseling by Antenatal Clients of a Tertiary Institution in Northern Nigeria
}

\author{
Oluwafumbi Medinat Olajide, Adekunle Olanrewaju Oguntayo*, Abimbola O. Kolawole \\ Department of Obstetrics and Gynaecology, Ahmadu Bello University Teaching Hospital, Zaria, Nigeria \\ Email: ${ }^{*}$ fayokunmi@yahoo.co.uk
}

Received 25 November 2014; accepted 2 December 2014; published 11 February 2015

Copyright (C) 2015 by authors and Scientific Research Publishing Inc.

This work is licensed under the Creative Commons Attribution International License (CC BY).

http://creativecommons.org/licenses/by/4.0/

(c) (i) Open Access

\begin{abstract}
Background: HIV testing and counseling (HTC) plays a central role in specific prevention of mother-to-child transmission (PMTCT) interventions, as these interventions depend on the woman knowing her HIV status. Over ninety percent of HIV infection in children is acquired through mother-to-child transmission. Objectives: This study assessed pregnant women's knowledge of HIV/AIDS, their awareness of HIV testing and counseling, and compared the uptake of HTC to the previously practiced voluntary counseling and testing (VCT) in a teaching hospital in northern Nigeria. Materials and Methods: A pre-tested, structured interview questionnaire was administered on a cross-section survey of $\mathbf{2 7 0}$ antenatal clients in Ahmadu Bello University Teaching Hospital (ABUTH), Nigeria. Information about knowledge of HIV/AIDS and attitude towards HTC was elicited among respondents. Results: Eighty-nine percent of respondents were aware of HIV/AIDS. The knowledge of route of disease transmission was high, with $87.4 \%$ and $81.1 \%$ of study participants mentioning sexual activity and mother-to-child transmission, respectively. Majority of respondents $(98.9 \%)$ were aware of HTC and approved of it $(91.1 \%)$ while $7.8 \%$ declined and the remaining $1.1 \%$ were undecided. Fourteen percent of respondents didn't approve of retesting in labour. Sixty-eight percent of respondents were aware of interventions to prevent mother-tochild transmission of HIV. Switching from VCT to HTC has dramatically improved the uptake of testing from $\mathbf{7 8 . 9 \%}$ in 2006 to $\mathbf{9 1 . 1 \%}$ in $\mathbf{2 0 1 2}$. Conclusion: Routine HIV testing and counseling is more acceptable than voluntary counseling and testing among antenatal clients. Although the awareness and uptake of HTC were quite high among the antenatal clients, there is still a need to intensify health education and incorporate husbands into the counseling session when necessary to convince the remaining minority who are still ignorant of the benefits of HTC.
\end{abstract}

\section{Keywords}

HIV Testing and Counseling (HTC), Voluntary Counseling and Testing (VCT)

\footnotetext{
"Corresponding author.
}

How to cite this paper: Olajide, O.M., Oguntayo, A.O. and Kolawole, A.O. (2015) Acceptability of HIV Testing and Counseling by Antenatal Clients of a Tertiary Institution in Northern Nigeria. Open Journal of Obstetrics and Gynecology, 5, 94-102. http://dx.doi.org/10.4236/ojog.2015.52013 


\section{Introduction}

Human Immunodeficiency Virus is a lentivirus (a member of the retrovirus family) that causes Acquired Immunodeficiency Syndrome (AIDS) [1] [2], a condition in humans in which progressive failure of the immune system allows life-threatening opportunistic infections and cancers to thrive. Heterosexual transmission accounts for nearly 80\% [3], while mother-to-child transmission (MTCT) and use of unsterilized sharps, infected blood and blood products account for $10 \%$ each [4].

The HIV (Human Immunodeficiency Virus)/AIDS pandemic is one of the most serious health crises the world is facing today, with a disproportionate burden on women and children. In 2009, 47.1\% (15.7 million) of the 33.3 million individuals living with HIV were women and 6.3\% (2.1 million) were children under 15 years old [5].

Sub-Saharan Africa has continued to bear the greatest burden of the HIV/AIDS epidemic [6]. Approximately, $67.6 \%$ of the total number of people living with HIV, $69.2 \%$ of the 2.6 million of the total new infections and $72.2 \%$ of the 1.8 million deaths in 2009 were from sub-Saharan Africa. Of the 370,000 new paediatric infection, sub-Saharan Africa accounted for about 90\% [5].

It was currently estimated that 3.3 million Nigerians were living with HIV, with 323,000 new infections in adults and 57,000 infants were born with it yearly. It is estimated that 360,000 children are living with HIV in the country, most of who became infected from their mothers. The national HIV sero-prevalence rate among pregnant women attending ANC was $1.8 \%$ in 1991 rising through $3.8 \%$ in $1994,4.5 \%$ in $1996,5.4 \%$ in 1999 , and 5.8\% in 2001 [7]. Thereafter, a decline was noticed through 5.0\% in 2003, 4.4\% in 2005, 4.6\% in 2008, and currently $4.1 \%$ in 2010 [5].

One of the goals of the June 2001 Declaration of Commitment of the United Nations General Assembly Special Session on HIV and AIDS was to reduce the proportion of infants infected with HIV by $20 \%$ by 2005 and $50 \%$ by 2010. The Nigerian national goal for PMTCT as contained in the 2003 AIDS Policy was to reduce the transmission of the HIV through MTCT by 50\% by the year 2010 and to increase access to quality HIV counseling and testing services by $50 \%$ by the same year. To achieve this goal, a comprehensive four-pronged strategy to prevent HIV infection among infants and young children was being implemented in Nigeria since 2001.

The specific PMTCT interventions are: HIV testing and counseling HTC (previously VCT voluntary counseling and testing), HIV and infant feeding counseling, modification of obstetric practices, administration of ARV prophylaxis to mother-child pair, care and support of HIV positive women and their families (PMTCT plus). HTC plays a central role in specific PMTCT interventions as these interventions depend on the woman knowing her HIV status.

In the absence of intervention, there is a $30 \%$ - $45 \%$ risk of transmission of HIV from mother to child during pregnancy, labour and delivery [5]. Over $90 \%$ of infection in children is acquired through MTCT [8]. UNAIDS estimate that 430,000 children were infected worldwide in 2008 (19\% of all new infections), primarily by this route [9].

The overall goal of the 2010-2015 National PMTCT scale-up plan is to contribute to improved maternal health and child survival through accelerated provision of comprehensive PMTCT services. The targets are: to provide access to at least $90 \%$ of all pregnant women to quality HIV counseling and testing by 2015; and to provide access to at least $90 \%$ of all HIV positive pregnant women to more efficacious ARV prophylaxis by the same year [10].

HIV testing is the process that determines whether a person is infected with HIV or not. HIV counseling is the confidential dialogue between individuals and their health care providers to help clients examine their risk of acquiring or transmitting HIV infection and to make informed decisions based on the information available to them.

The essential components of HTC for PMTCT include: pre-test information, HIV testing and the same-day result, post-test counseling and follow-up counseling. The two types of HIV testing include: the "opt-in” or voluntary counseling and testing VCT; and "opt-out” or routine HIV testing and counseling HTC. The recommended approach to testing and counseling is the "opt-out” approach.

With "opt-in" testing, a woman may be informed that a test is available, but will only be given one if they specially request for it. Often, this means that only women who are worried about HIV will agree to be tested. Many women worry that they will be stigmatized for accepting the test. 
With "opt-out" testing, HIV testing is offered as part of routine tests in the antenatal clinics, but women have the right to refuse taking the test. All pregnant women receive an HIV testing, after being counseled, unless they specifically state that they do not want one. Any woman who receives an HIV positive result will then be counseled again and given appropriate treatment if necessary. The recommended approach to testing and counseling is the "opt-out" approach.

"Opt-out" testing is generally considered more effective than "opt-in" and uptake tends to be much higher [11]. Removing the special status often given to HIV testing helps make it more acceptable. Numerous studies have found that switching from VCT to routine HTC can dramatically improve take-up of testing in PMTCT programs. For example, at one hospital in rural Uganda, the proportion of pregnant women with documented HIV status at discharge doubled from $39 \%$ to $88 \%$ after routine HTC was introduced [12]. When Botswana changed its testing procedure nationwide in 2004, it immediately increased testing rates from $75 \%$ to $90 \%$ [13]. More studies in developed countries have shown that when pregnant women are offered a routine HTC on an “opt-out" basis, 89\% - 95\% agree to have one [14]-[16].

HIV testing is critical because women who do not know they are HIV positive cannot benefit from interventions. In developed countries, MTCT has been virtually eliminated, due to effective voluntary testing and counseling, access to antiretroviral therapy, safe delivery practices, and widespread availability and safe use of breast-milk substitutes. If these interventions are used worldwide, they would save the lives of thousands of children each year.

High "opt-out" rate has been noticed in the ABUTH statistics, with a monthly rate of $7.4 \%-17.9 \%$ and an average rate of $12.3 \%$ in 2011. After about 5 years of HTC and 5 years of VCT services in ABUTH, Zaria, it is necessary to assess the effectiveness of the "opt-out" approach over the "opt-in", in order to determine the progress made so far.

The study was set out to assess the uptake/acceptability of HIV testing and counseling by antenatal clients by determining the level of awareness of HTC among pregnant women, the number of those who opts out and their reasons, and finally compare the uptake of HTC relative to the previously practiced VCT.

Study design: the study was conducted in Zaria, northern Nigeria. 270 consenting pregnant women attending the antenatal clinic of ABUTH, Zaria constituted the study population.

A descriptive and cross-sectional survey was carried out. Pre-tested, and structured questionnaire with openand close-ended questions were administered to respondents.

The subjects for the study were recruited from the antenatal clinics using convenience, non-probability sampling technique, in the form of consecutive pregnant women who meet the inclusion criteria. Each respondent was duly counseled, and consent was sought before the questionnaires were administered. The reference prevalence used for the sampling size estimation was from the study of acceptability of VCT by antenatal clients in Aminu Kano Teaching Hospital, Kano which was 81\% [17].

Statistical analysis was done with SPSS version 20, using simple statistical ratios and percentages.

\section{Results}

\subsection{Sociodemographic Characteristics}

Of the 270 questionnaires issued, 250 were returned correctly filled giving a response rate of $92.6 \%$. Sociodemographic characteristics of the respondents are outlined in Table 1. Majority of the respondents (57\%) were between the ages of 21 - 30 years. 268 (99.3\%) of the respondents were married, among which 161 (59.6\%) were from a polygamous setting. Majority of the married respondents $(87 \%)$ were in their $1^{\text {st }}$ order of marriage while only $5.9 \%$ were in their $2^{\text {nd }}$ order. Thirty percent (30.4\%) were primigravida,

\subsection{Knowledge of HIV/AIDS}

Two hundred and forty (88.9\%) of participants had heard of HIV/AIDS infection while 27 (10\%) had not (see Table 2). Among the $81.1 \%$ that said they knew the cause of HIV infection, $88.6 \%$ were correct about the transmission through blood and body fluids, while $87.4 \%$ of respondents knew that HIV infection can be transmitted via unprotected sexual intercourse. $81.1 \%$ knew about mother-to-child transmission, while $78.5 \%$ and 77.4\% knew about transmission through blood transfusion and unsterilized sharp objects respectively (Figure 1). 
Table 1. Sociodemographic characteristics.

\begin{tabular}{|c|c|c|}
\hline Age Distribution (years) & Respondents (n) & Respondents (\%) \\
\hline$<20$ & 31 & $11.9 \%$ \\
\hline $21-30$ & 154 & $59.2 \%$ \\
\hline $31-40$ & 70 & $26.9 \%$ \\
\hline 41 and above & 5 & $1.9 \%$ \\
\hline \multicolumn{3}{|l|}{ Marital Status } \\
\hline Married & 268 & 99.3 \\
\hline Single & 1 & 0.4 \\
\hline Separated & 1 & 0.4 \\
\hline \multicolumn{3}{|l|}{ Type of Marriage } \\
\hline Monogamous & 161 & 59.6 \\
\hline Polygamous & 89 & 33 \\
\hline \multicolumn{3}{|l|}{ Order of Marriage } \\
\hline $1^{\mathrm{st}}$ & 235 & 87 \\
\hline $2^{\text {nd }}$ or more & 16 & 5.9 \\
\hline \multicolumn{3}{|l|}{ Parity } \\
\hline Nulliparous & 15 & 5.6 \\
\hline Primgravida & 82 & 30.4 \\
\hline Primiparous & 62 & 23 \\
\hline Multiparous & 73 & 27 \\
\hline Grandmultiparous & 33 & 12.2 \\
\hline \multicolumn{3}{|l|}{ Religion } \\
\hline Christian & 68 & 25.2 \\
\hline Muslim & 199 & 73.7 \\
\hline \multicolumn{3}{|l|}{ Occupation } \\
\hline Civil servant & 71 & 26.3 \\
\hline Business & 29 & 10.7 \\
\hline Housewife & 87 & 32.2 \\
\hline Student & 45 & 16.7 \\
\hline Farmer & 12 & 4.4 \\
\hline Others & 24 & 8.9 \\
\hline \multicolumn{3}{|l|}{ Highest Educational Level } \\
\hline None & 5 & 1.9 \\
\hline Quranic & 14 & 5.2 \\
\hline Primary & 21 & 7.8 \\
\hline Secondary & 78 & 28.9 \\
\hline
\end{tabular}




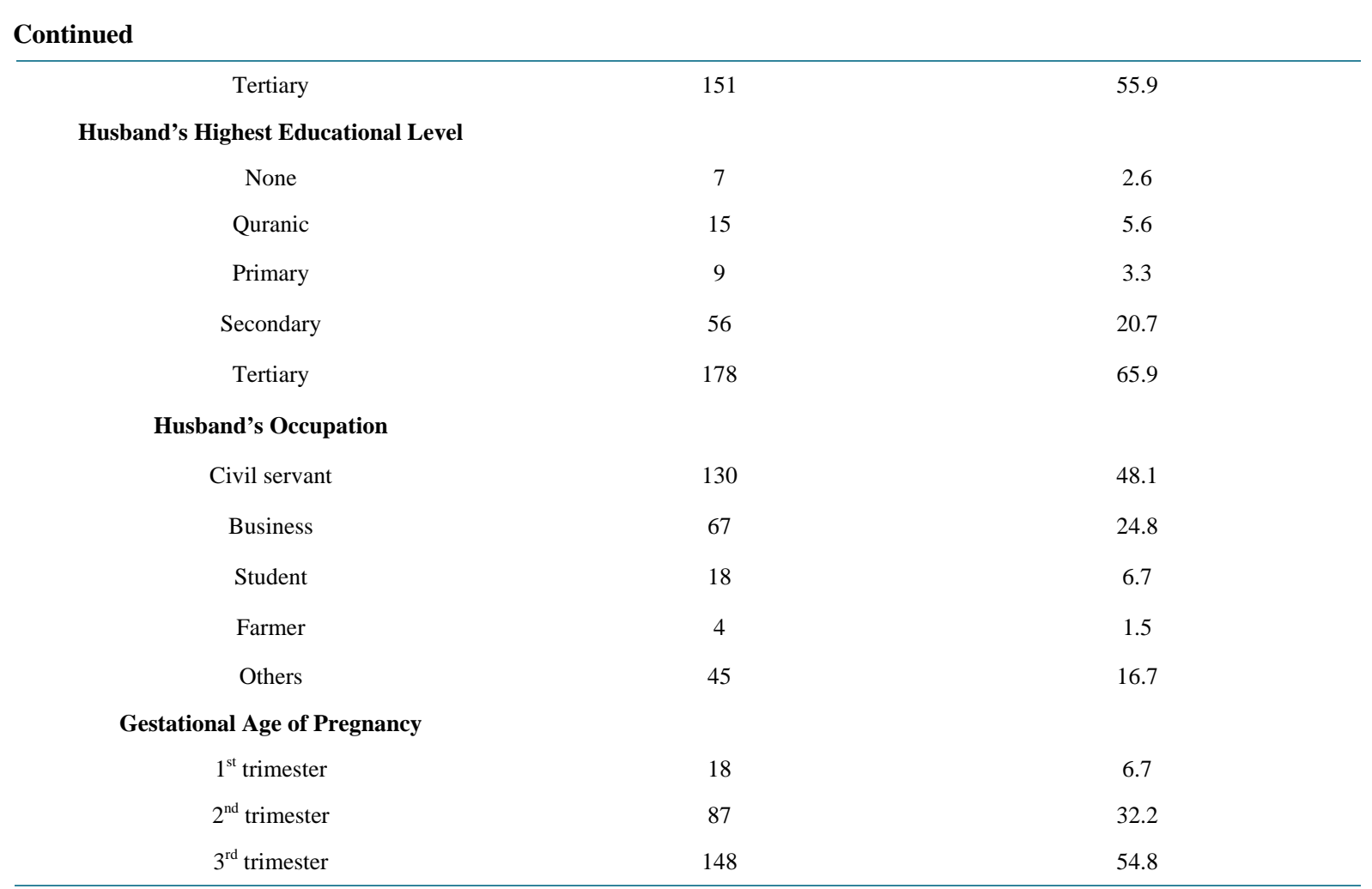

Abbreviation: n, number.

Table 2. Knowledge of HIV/AIDS infection.

\begin{tabular}{ccc}
\hline Question & Yes (n) & Yes (\%) \\
\hline Ever heard of HIV/AIDS? & 240 & 88.9 \\
Do you know the cause of HIV? & 219 & 81.1 \\
Aware of possibility of HIV infection in an \\
$\begin{array}{c}\text { asymptomatic person } \\
\text { Aware that a positive mother can infect her child }\end{array}$ & 189 & 70 \\
\hline
\end{tabular}

Abbreviation: n, number.

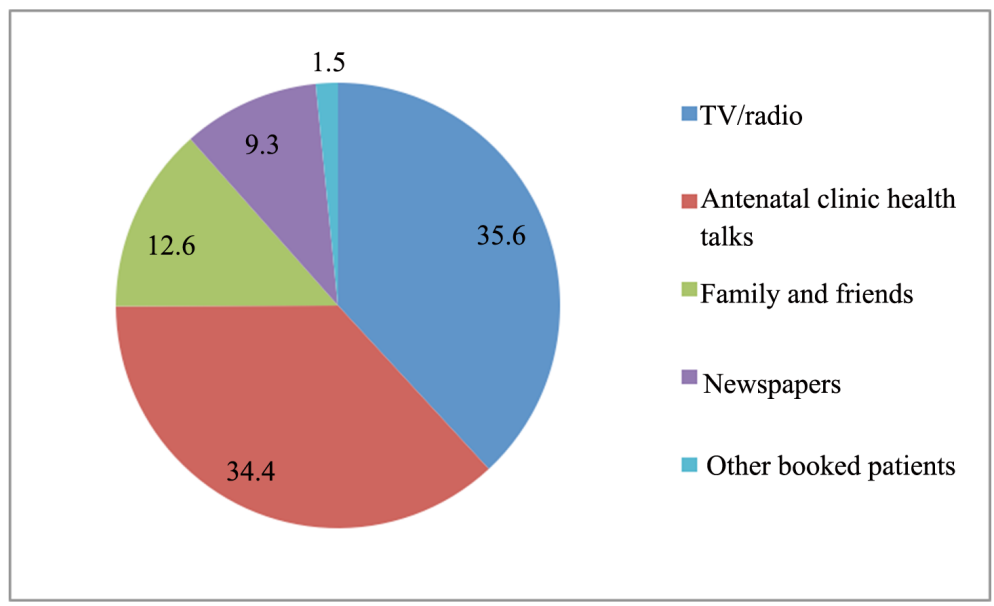

Figure 1. What is your source of information? 


\subsection{Awareness and Uptake of HIV Testing and Counseling}

Most (98.9\%) of the respondents were aware of HIV testing and 98.1\% were aware of the availability of such test (HTC services) in ABUTH, Zaria. 248 (91.9\%) of respondents had been informed of the test at the antenatal clinic. Majority (83\%) of respondents acknowledged that the information given before the HIV test was carried out was adequate enough while $12.2 \%$ disagreed to that (Table 3). The reasons for disagreeing included inadequate time (20.9\%), lack of confidentiality (16.3\%), inadequate information (16.3\%) and poor language interpretation (14\%).

Out of the 21 respondents that didn't agree to do the test, 14 (66.7\%) said they would have agreed to do the test if they had been informed in a different way while 4 (19\%) still declined (Table 3). 3 (14.3\%) respondents however, didn't give any reason.

\subsection{Awareness of Interventions}

Majority of the respondents (87.4\%) were aware of the availability of drugs for the treatment of HIV/AIDS while $68.5 \%$ were aware of interventions to prevent mother-to-child transmission of HIV.

The interventions mentioned by the respondents were avoiding breastfeeding (44.7\%), antiretroviral drugs (29\%), early antenatal care and HIV testing (8.4\%), hospital delivery (7.8\%), caesarean delivery (5.9\%), exclusive breastfeeding for 6 months (3.4\%) and modified obstetric practice (1.1\%) (Table 4).

\section{Discussion}

The level of awareness of HIV infection among the antenatal clients in this study was high but relatively low when compared with 99\% in Nnewi study [18], 100\% in Kano [17], Ekiti [19] (all in Nigeria) and China [20]

Table 3. HIV testing and counseling.

\begin{tabular}{|ccc|}
\hline Question & Yes (n) & Yes (\%) \\
\hline Aware of HIV testing & 267 & 98.9 \\
Aware of availability of HTC in ABUTH & 265 & 98.1 \\
Have you been informed about the test? & 248 & 91.9 \\
Have you decided to undertaken the test? & 246 & 91.1 \\
$\quad$ Is the information given adequate? & 224 & 63.7 \\
Would you have agreed to do the test if informed $\quad$ differently? & 14 & 83.3 \\
Do you desire more information? & 225 & 82.6 \\
\hline
\end{tabular}

Abbreviation: n, number.

Table 4. Interventions mentioned by respondents.

\begin{tabular}{cc}
\hline Interventions & Percentage (\%) \\
\hline Avoiding breastfeeding & 44.7 \\
Antiretroviral drugs & 29 \\
Early antenatal care and HIV testing & 8.4 \\
Hospital delivery & 7.8 \\
Caesarean delivery & 5.9 \\
Exclusive breastfeeding for 6 months & 3.4 \\
Modified obstetric practice & 1.1 \\
\hline
\end{tabular}


respectively. Majority of the antenatal clients (87.4\%) were aware of unprotected sexual intercourse as a major route of transmission of the virus, which is higher than 63\% from Benin [21] (Nigeria) and 70.9\% from Kano [17]. Knowledge of transmission through mother-to-child (81.1\%) and through blood (78.5\%) was also high. This is much higher than the $64 \%$ of pregnant women who were aware of mother-to-child transmission in China [20], 68\% in Ekiti [19], 76.9\% in Nnewi [18], but lower than figures of 95\% and 93.3\% reported among antenatal clients in Kano [17] and Lagos [22] (Nigeria) respectively. However, 11.1\% of respondents had a misconception that HIV could be transmitted through mosquito bites, which is similar to $11 \%$ obtained in Kano. Over two third of the antenatal clients (70\%) were aware that HIV infection could be present in an asymptomatic person as compared to $42 \%$ obtained from Kano.

Almost all the respondents (98.9\%) were aware of HIV testing. This is much higher with HIV testing and counseling HTC ("opt-out" method) being practiced now in ABUTH as compared to 88\% from a local study in ABUTH in 2006 when Voluntary Counseling and Testing VCT ("opt-in" method) was being practiced [23]. This is also higher than the $55 \%$ reported from Kano when VCT was being practiced. This is attributable to the information given to all pregnant women in the antenatal clinic, using the "opt-out" approach.

The uptake of HTC in this study was high, as $91.1 \%$ of the antenatal clients that were informed had either undertaken the test or agreed to do so. This is higher than the uptake of VCT of 78.9\% in 2006 in ABUTH Zaria, $76 \%$ in Maiduguri [24] (Nigeria) and 81\% in Kano. It is however lower than 96.1\% reported among antenatal clients in Lagos [22]. There is a significant increase in uptake of HIV testing with HCT as compared with VCT. This is expected as the antenatal clinic provides an appropriate opportunity for educating women about HIV/AIDS. Knowledge of the pregnant woman's HIV status will enable her to benefit from treatment for herself and interventions for prevention of mother-to-child transmission PMTCT.

Though the level of uptake of HIV testing has improved with the introduction of HTC, the reasons for refusal still remain similar to those when VCT was being practiced in ABUTH Zaria and even Kano. The most common reasons included that the test had earlier been done outside pregnancy, marriage security, fear of positive result, need to discuss with husband and believing they are not at risk of the infection. There is therefore, the need to intensify health education and incorporate husbands into the counseling session when necessary.

Eighty three percent of the antenatal clients acknowledged that the information given before the HIV test was carried out was adequate, while $12.2 \%$ disagreed, the major reasons of which were, inadequate time, inadequate information, lack of confidentiality and poor language interpretation. Suggestions made by the clients to improve the uptake of HTC included: giving detailed information about HIV, allotting more time to the counseling session, use of public address system, opportunity to ask questions especially in private, counseling of husbands where necessary and more friendly attitude of counselors.

Over seventy seven percent (77.8\%) of clients who initially declined the test said they would have agreed to do it if they were informed differently. This shows the importance of the content of the information given and the manner in which it is given. Eighty two percent (82.6\%) wouldn't mind being retested in labor while 13.7 declined mainly because they felt there was no need to repeat the test. Universal HIV testing of pregnant women is the key to prevention of MTCT of HIV. Repeat testing at labour and delivery is an additional strategy to further reduce the rate of perinatal HIV transmission. Antenatal clients should be made more aware of the window period during the antenatal health talks.

There was a high level of awareness of availability of drugs (87.4\%) for the treatment of HIV and interventions (68.5\%) to prevent mother-to-child transmission amongst which were, use of anti-retroviral drugs, avoiding breastfeeding, exclusive breastfeeding, early antenatal care and HIV testing, hospital delivery, caesarean delivery, and modified obstetric practice. This is not surprising as many of the antenatal clients are educated and are also informed through the HTC program. Respondents were however more aware of the avoidance of breastfeeding (44.7\%) than they were of the use of antiretroviral drugs (29\%) as strategies for preventing mother-to-child transmission. Prevention of mother-to-child transmission of HIV is most effective when antiretroviral drugs are received by the mother during pregnancy and continued through delivery and then administered to the infant after birth.

\section{Conclusion}

This study found that more than two-third of the antenatal care attendees of ABUTH had adequate knowledge of HIV/AIDS. However, misconceptions, fear and gaps in knowledge regarding HIV/AIDS are still prevalent. 
Switching from VCT (“opt-in”) to routine HTC (“opt-out”) has dramatically improved the take-up of testing in PMTCT program in ABUTH, Zaria from 78.9\% in 2006 to 91.1\% now. The reasons for opting out still remain the same with the VCT and the HTC approach. These findings suggest the need to improve on the information and counseling given to antenatal clients regarding HIV/AIDS and for the health care providers to imbibe a better attitude. Also, husbands should be incorporated into the counseling session whenever necessary. Although the acceptability of HTC is quite high, there is a need to intensify health education to convince the remaining minority who are still ignorant of the benefits of HTC.

\section{References}

[1] Weiss, R.A. (1993) How Does HIV Cause AIDS? Science, 260, 1273-1279. http://dx.doi.org/10.1126/science.8493571

[2] Douek, D.C., Roederer, M. and Koup, R.A. (2009) Emerging Concepts in the Immunopathogenesis of AIDS. Annual Review of Medicine, 60, 471-484. http://dx.doi.org/10.1146/annurev.med.60.041807.123549

[3] United Nations General Assembly Special Session (UNGASS) (2010) Country Progress Report, Nigeria.

[4] Egesie, J. and Egesie, G. (2011) Seroprevalence of Human Immunodeficiency Virus (HIV) among Blood Donors in Jos-Nigeria. In: Barros, E., Ed., HIV-Infection: Impact, Awareness and Social Implications of Living with HIV/AIDS, In Tech.

[5] Federal Ministry of Health (2010) National Guidelines on Prevention of Mother-to-Child Transmission of HIV (PMTCT). Federal Ministry of Health, Nigeria.

[6] UNAIDS (2011) World AIDS Day Report. UNAIDS, Geneva.

[7] Adeyi, O., Kanki, P.J., Odutolu, O., et al. (2006) AIDS in Nigeria: A Nation on the Threshold. Chapter 2: The Epidemiology of HIV/AIDS in Nigeria. Harvard Centre for Population and Development Studies, Cambridge.

[8] UNAIDS (2010) Report on the Global AIDS Epidemic. UNAIDS, Geneva.

[9] UNAIDS Report (2009). http://unaids.org/pub/Report/2009/JC1700 Epi Update 2009 en.pdf

[10] Adebanjo, T. National HIV/AIDS Strategic Framework/Plan 2010-2015. National Agency for the Control of AIDS (NACA), Nigeria.

[11] Centre for Disease Control and Prevention (2002) HIV Testing among Pregnant Women—United States and Canada, 1998-2001. Morbidity and Mortality Weekly Report, 51, 1013-1016.

[12] Homsy, J., Kalamya, J.N., Obonyo, J., Ojwang, J., Mugumya, R., Opio, C. and Mermin, J. (2006) Routine Intrapartum HIV Counseling and Testing for Prevention of Mother-to-Child Transmission of HIV in a Rural Ugandan Hospital. JAIDS Journal of Acquired Immune Deficiency Syndromes, 42, 149-154. http://dx.doi.org/10.1097/01.qai.0000225032.52766.c2

[13] Centre for Disease Control and Prevention (CDC) (2004) Introduction of Routine HIV Testing in Prenatal CareBotswana, 2004. Morbidity and Mortality Weekly Report, 53, 1083-1086.

[14] Schuman, P., Jones, T.B., Laken, M.P., Ohmit, S. and Marbury, C. (2004) Voluntary HIV Counseling and Testing of Pregnant Women-An Assessment of Compliance with Michigan Public Health Status. Medscape General Medicine, 6, 52 .

[15] Simpson, W.M. (1999) Antenatal HIV Testing: Assessment of a Routine Voluntary Approach. British Medical Journal, 318, 1660-1661. http://dx.doi.org/10.1136/bmj.318.7199.1660

[16] Bitnun, A., King, S.M., Ameson, C. and Read, S.E. (2002) Failure to Prevent Perinatal HIV Infection. Canadian Medical Association Journal, 166, 904-905.

[17] Iliyasu, Z., Kabir, M., Galadima, H.S., Abubakar, I.S. and Aliyu, M.H. (2005) Awareness and Attitude of Antenatal Clients towards HIV Voluntary Counseling and Testing in Aminu Kano Teaching Hospital, Kano, Nigeria. Nigerian Journal of Medicine, 14, 27-32.

[18] Igwegbe, A.O. and Ilika, A.L. (2005) Knowledge and Perceptions of HIV/AIDS and Mother to Child Transmission among Antenatal Mothers at Nnamdi Azikiwe University Teaching Hospital, Nnewi. Nigerian Journal of Clinical Practice, 8, 97-101.

[19] Abiodun, M.O., Ijaiya, M.A. and Aboyeji, P.A. (2007) Awareness and Knowledge of Mother-to-Child Transmission of HIV among Pregnant Women. Journal of the National Medical Association, 99, 758-763.

[20] Luo, Y. and He, G.P. (2008) Pregnant Women’s Awareness and Knowledge of Mother to Child Transmission of HIV in South Central China. Acta Obstetricia et Gynecologica Scandinavica, 87, 831-836. http://dx.doi.org/10.1080/00016340802226342

[21] Osazuwa, F., Dirisu, J.O. and Okuoghae, P.E. (2012) Early Determination of HIV Status by Routine Voluntary Coun- 
seling and Testing in Benin City, Nigeria. North American Journal of Medical Sciences, 4, 99-103. http://dx.doi.org/10.4103/1947-2714.93378

[22] Ekanem, E.E. and Gbadegesin, A. (2004) Voluntary Counseling and Testing (VCT) for Human Immunodeficiency Virus: A Study on Acceptability by Nigeria Women Attending Antenatal Clinics. African Journal of Reproductive Health, 8, 91-100. http://dx.doi.org/10.2307/3583183

[23] Ajayi, V.D. (2007) Acceptability of Voluntary Counseling and Testing: A Thesis Submitted to the National Postgraduate Medical College of Nigeria (NPMCN) in Partial Fulfillment of the Requirements for the Part 1 Examination of NPMCN, Unpublished.

[24] Chama, C.M., Audu, B.M. and Kyari, O. (2004) Prevention of Mother-to-Child Transmission of HIV of Maiduguri, Nigeria. Journal of Obstetrics \& Gynaecology, 24, 266-269. http://dx.doi.org/10.1080/01443610410001660760 
Scientific Research Publishing (SCIRP) is one of the largest Open Access journal publishers. It is currently publishing more than 200 open access, online, peer-reviewed journals covering a wide range of academic disciplines. SCIRP serves the worldwide academic communities and contributes to the progress and application of science with its publication.

Other selected journals from SCIRP are listed as below. Submit your manuscript to us via either submit@scirp.org or Online Submission Portal.
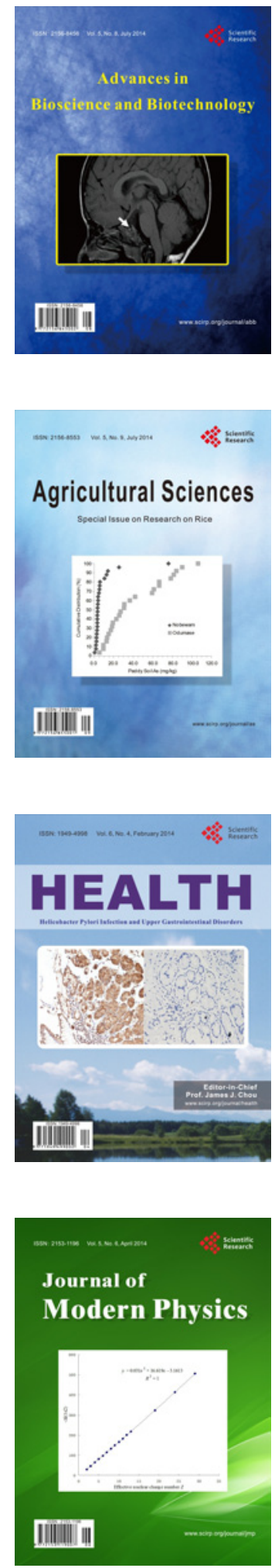
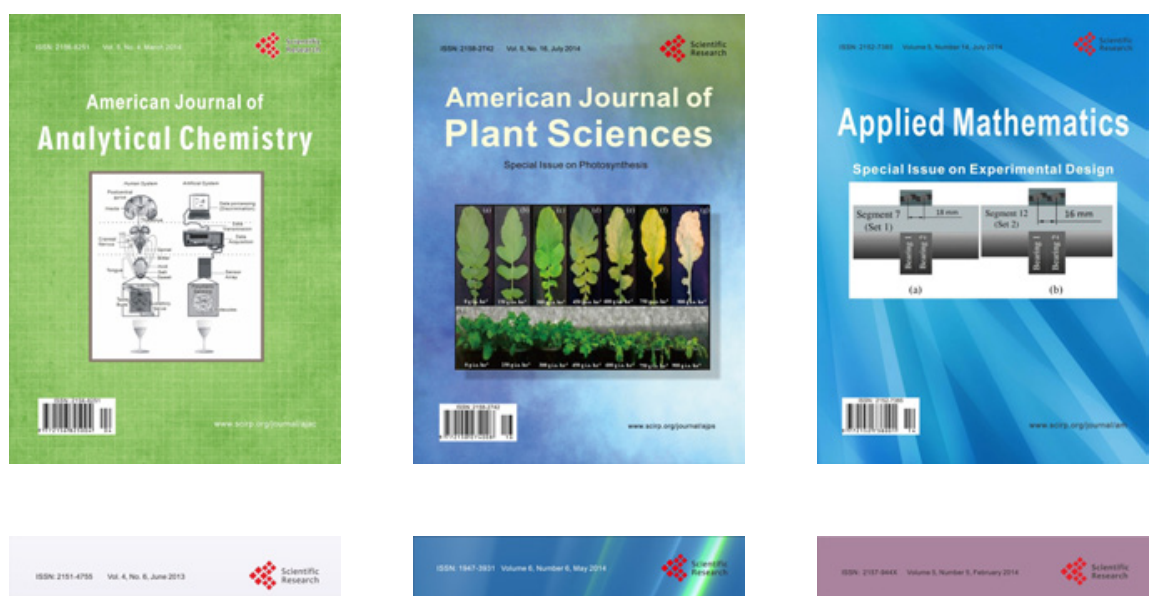

Creative Education
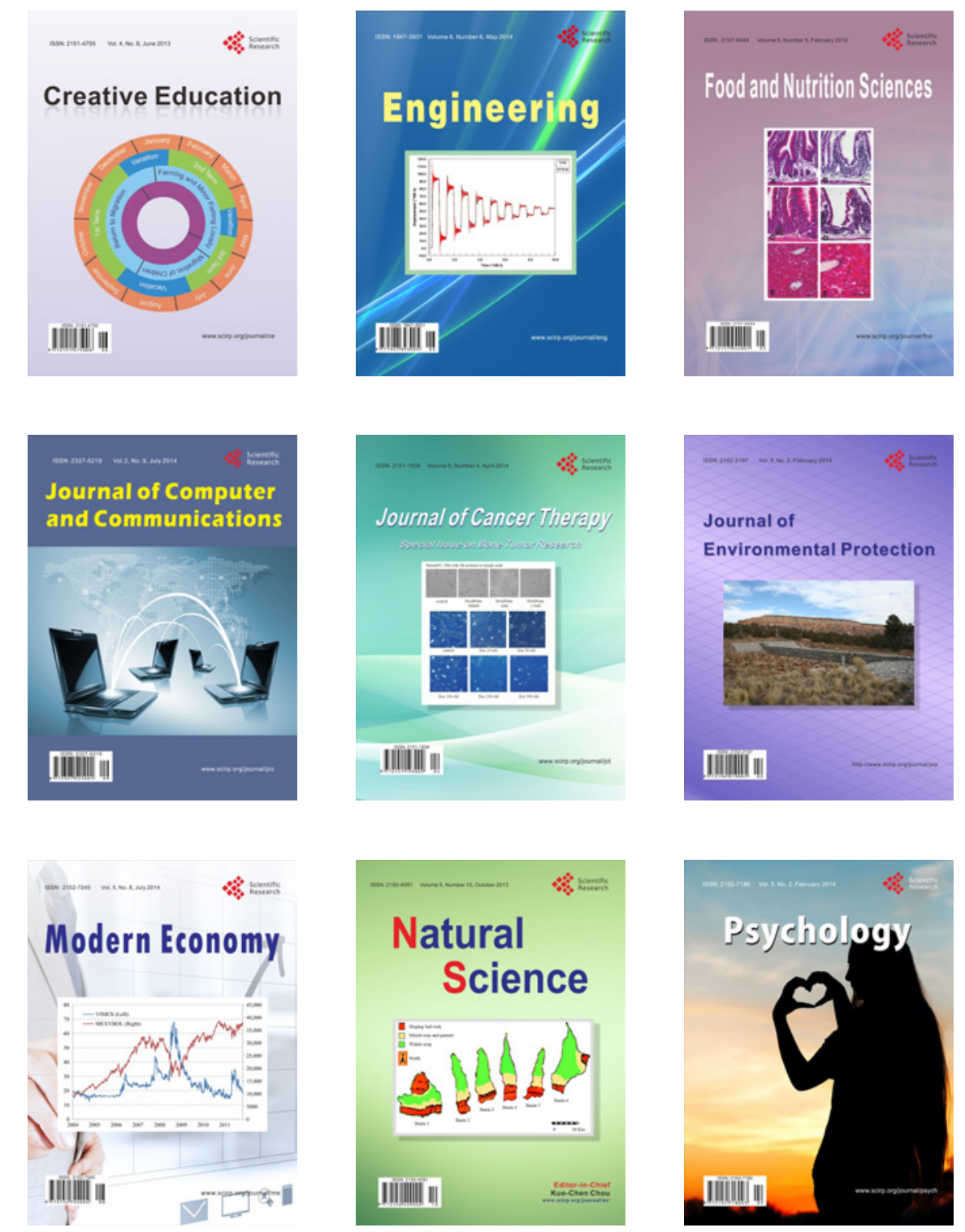